\title{
Lance Armstrong's Era of Performance - Part II: Revisiting His Time Trial Wins
}

\author{
Hein F.M. Lodewijkx* , Arjan E.R. Bos \\ Faculty of Psychology and Educational Sciences, Open University of the Netherlands, Heerlen, the Netherlands \\ *Corresponding author: Hein.Lodewijkx@ou.nl
}

Received October 04, 2014; Revised October 28, 2014; Accepted November 03, 2014

\begin{abstract}
This archival study $(N=100)$ compared Lance Armstrong's time trial wins to victories demonstrated by all former multiple Grand Tour winners (1949-1995; Coppi, Anquetil, Merckx, Hinault, Indurain) and by riders who won similar races in the three major European Grand Tours (Tour de France, Giro d'Italia, and Vuelta a España) from 2006 to 2013, who were either involved in doping affairs or not. Regression analyses yielded a non-significant $M=142$ seconds difference between Armstrong vs. the aggregated other riders $\left(\Delta R^{2}=.001, p=.20\right)$. The effect emerged after controlling for the influence of competition year $(b=-12.23 \mathrm{~s}$ per year, $\Delta R 2=.045, p \leq .001)$ and trial distances $\left(b=84.64 \mathrm{~s}\right.$ per kilometer trial distance, $\left.\Delta R^{2}=.933, p \leq .001\right)$ on the variation in riders' speed. Furthermore, Armstrong along with other riders who were suspended for doping use or who acknowledged having used doping in the 2006-2013 periods did not outperform riders who were not involved in doping affairs during the same years $\left(M=-68 \mathrm{~s}, \Delta R^{2}=.01, p=.35\right)$. Findings disprove the argument from ignorance, a false logic which refers to the often heard opinion that cyclists' performances over time (including Armstrong's wins) are mainly determined by their use of increasingly potent doping aids. However, in contrast to this logic, the distances of the time trials constitute the main determinant of riders' performances rather than the year in which they competed, and riders engaged in doping affairs did not significantly outperform riders who were not.
\end{abstract}

Keywords: doping, professional cycling, time trial performance

Cite This Article: Hein F.M. Lodewijkx, and Arjan E.R. Bos, "Lance Armstrong’s Era of Performance Part II: Revisiting His Time Trial Wins.” American Journal of Sports Science and Medicine, vol. 2, no. 5 (2014): 194-201. doi: 10.12691/ajssm-2-5-4.

\section{Introduction}

Professional cycling is regarded as one of the mostdoping-prone disciplines in sports [1]. This is illustrated by massive doping schemes that plagued the cycling world the last two decades, such as the 1998 Festina affair [2], the 2006 Operaçion Puerto blood doping affair [3], and the 2013 Armstrong affair [4,5]. In consequence of USADA's doping charges [4,5] against the American ex-cyclist, in January 2013 Lance Armstrong conceded he doped during his career. As a result, the International Cycling Union (UCI) - the sport's governing body - stripped him of all his sportive victories including his seven Tour de France wins.

In the wake of the affair, Lodewijkx and Verboon [6] examined whether Armstrong's time trial wins, realized on flat and rolling terrain in the Tour de France from 1999 to 2005, were superior to victories of riders who, from 1934 to 2010, rode time trials in the three major European tours (Tour de France, Giro d'Italia, and Vuelta a España) with distances that were equivalent to Armstrong's distances (50-61 km). The study knowingly settled on riders' time trial rather than final accomplishments as the evaluation criterion, since the former performances are not biased by the forces exerted by the total group of riders participating in three-week, multi-stage cycling races such as the three main tours [7,8]. Time trials are considered the moment of truth in cycling. Riders in person race against the clock and compete for the fastest time, making it impossible to profit from the collective labors of collaborating riders in the race through drafting (benefitting from other riders' slipstream). Because time trial performances exclusively rest on individual riders' power and stamina, we argued that this would enhance the likelihood to indirectly identify the influence of ergogenic (or performance-enhancing) doping agents on the achievements of the disputed American ex-racer. Initially, the study [6] revealed that Armstrong indeed raced significantly faster than the other riders did. However, after statistically controlling for the year in which riders won their trial, findings yielded no significant differences in speed between riders anymore. Analyses further indicated that none of Armstrong's victories constituted statistical outliers.

These findings puzzled us. After all, Armstrong's affirmations make clear that he willfully attempted to boost his performances by doping aids such as epo, blood transfusions, and testosterone [4,5]. Yet, when reckoning the variation in riders' evolution in speed over time, findings of the time trial study credibly indicated that his accomplishments were not extraordinary. The same study also made us aware of a false logic — the argumentum ad 
ignorantiam —used in societal discussions about doping, aroused by the Armstrong affair. These 'arguments from ignorance' pose that "something is true only because it has not been proved false, or that something is false only because it has not been proved true" [9]. It refers to the frequently used statement that riders' progress in speed can mainly be attributed to the use of progressively stronger and advanced doping means and methods. However, archival research demonstrates inconclusive empirical evidence concerning this relationship. Some studies support this relationship [7,10], while other studies are more critical [6,11,12,13].

To evaluate findings and conclusions of the foregoing Armstrong time-trial study and to validate the reasoning used in the appeal to ignorance, in this contribution we chose to contrast Armstrong's time trial wins to victories realized by all former multiple Grand Tour winners (Coppi, Anquetil, Merckx, Hinault, and Indurain; 19491995), as well as all riders who won similar races in the three tours from 2006 to 2013. As we will describe below, the current study differs from the previous Armstrong study on two important variables. For the main part the sample consists of a different group of cyclists who all performed after World War II and faced a much larger variation in trial distances. Furthermore, all former multiple Grand Tour winners were renowned time trialists which make them appropriate comparison persons against whom we can critically evaluate Armstrong's wins. The 2006-2013 periods constitute the years following Armstrong's supremacy in professional road racing. This permits us, first, to appraise whether riders' victories in the post-Armstrong period differ in any respect from achievements of the American ex-cyclist. Second, many riders in this era were suspended for doping use or disclosed afterwards that they resorted to the use of banned doping aids during their active career. This enables us to evaluate whether the achievements delivered by the latter riders (the Doping Group / Armstrong) differ from the performances of riders who were not associated with doping affairs during the same era (the No Doping Group).

As with the prior time trial studies [6,11], an analysis of the historic variation in riders' individual performances will provide answers to three research questions. First, assuming that Armstrong's doping aids indeed strongly boosted his performances $[4,5,14]$, it can be expected that his time trial wins will be superior to other riders. Second, based on the logic used in the appeal to ignorance we expect a strong relationship between the year in which riders competed and their time trial performances. Third, regarding riders' accomplishments in the 2006-2013 periods, we expect that performances of the Doping Group / Armstrong will be superior to performances of riders of the No Doping Group.

\section{Method}

\subsection{Design, Sample, Descriptive Statistics, and Correlations}

We retrieved information concerning our variables from the archival records comprised by the French "Association Mémoire du Cyclisme" [15]. Team time trials, (semi-) mountain time trials (racing uphill) and prologues (since 1967 the first stage in the tours of approximately $8 \mathrm{~km}$ ) were not included in the study. Team trials do not measure individual performances. The number of observations of prologues would be too small to reach valid conclusions [6], while (semi-)mountain time trials cannot be compared with time trials on flat or rolling terrain $[11,16]$. Table 1 presents descriptive statistics of the variables we measured. It also gives an overview of riders in the Doping and the No Doping Group as well as of riders who faced (semi-) mountain trials, a circumstance which considerably reduced their overall speed [17].

Table 1. Descriptive Statistics of Time Trials and Riders' Performances

\begin{tabular}{|c|c|c|c|c|c|c|}
\hline Riders & Trials $^{1}$ & Years (range) & Distance (range) & $M_{\text {distance }}{ }^{2}$ & $M_{\text {time }}(S D)^{3}$ & $M_{k m / h}(S D)$ \\
\hline F. Coppi & 5 & 1949-1952 & $60-137$ & $87.00 \mathrm{a}$ & $2: 13: 19(0: 51: 45)$ & 39.51 (1.73) \\
\hline J. Anquetil & 14 & $1957-1964$ & $9.8-74.5$ & $45.08 \mathrm{a}$ & 1:00:37 (0:27:39) & $44.53(2.20)$ \\
\hline E. Merckx & 19 & $1969-1975$ & $8.2-56$ & $23.93 b$ & 0:30:43 (0:20:00) & $47.18(2.13)$ \\
\hline B. Hinault & 17 & 1978-1986 & $22-75$ & $45.54 a$ & $0: 59: 58(0: 20: 36)$ & 45.77 (2.18) \\
\hline M. Indurain & 11 & 1991-1995 & $28-73$ & $55.86 a$ & 1:08:37 (0:16:22) & 48.79 (1.99) \\
\hline L. Armstrong & 7 & 1999-2005 & $50-61$ & $56.21 \mathrm{a}$ & 1:08:22 (0:03:39) & 49.37 (2.46) \\
\hline Doping Group4 & 11 & 2006-2009 & $27.5-57$ & $44.97 b$ & $0: 53: 44(0: 12: 29)$ & $50.10(1.25)$ \\
\hline No Doping Group5 & 16 & 2007-2013 & $14.4-53.5$ & $36.56 b$ & 0:43:30 (0:14:17) & $50.43(2.84)$ \\
\hline Total & 100 & $1949-2013$ & $8.2-137$ & 43.83 & $0: 56: 23(0: 30: 09)$ & $47.36(3.47)$ \\
\hline
\end{tabular}

Notes:

${ }^{1}$ Based on [17], we excluded nine trials with extremely hilly courses (semi-mountain time trials): Coppi (Giro 1952); Anquetil (Vuelta 1963); Merckx (Giro 1969); Bruseghin (Giro 2008); Menchov (Giro 2009); Larsson (Giro 2010); Dowsett (Giro 2013); Kessiakoff (Vuelta 2012); and Cancellara (Vuelta 2013).

${ }^{2}$ Mean distances of time trials without a common superscript differ significantly, $\mathrm{p} \leq .05$ (by Games-Howell test). In these pair wise comparisons we contrasted Armstrong's trial distances to all other riders.

${ }^{3}$ Time $=$ time performances in hours, minutes and seconds; $\mathrm{km} / \mathrm{h}=$ kilometer per hour performances.

${ }^{4}$ This group concerns eleven riders who were suspended for doping use or who confessed afterwards that they used doping during their career: Honchar (two trials Tour 2006); Ullrich (Giro 2006); Vinokourov (Vuelta 2006, Tour 2007); Millar (Vuelta 2006); Leipheimer (Tour 2007, Vuelta 2008); Schumacher (two trials Tour 2008); and Contador (Tour 2009).

${ }^{5}$ This group concerns Salvodelli (Giro 2007); Sanchez (Vuelta 2007); Grabsch (Vuelta 2007); Pinotti (Giro 2008, 2012); Konovalovas (Giro 2009); Cancellara (Vuelta 2009, Tour 2010); Millar (Vuelta 2009, Giro 2011, realized after his doping suspension); Velits (Vuelta 2010); Martin (Tour 2011, Vuelta 2011, Tour 2013); Wiggins (two trials Tour 2012). 
We assembled data concerning Armstrong's time trial achievements which he realized in his seven Tour wins in addition to performances demonstrated by Fausto Coppi in five Giros and two Tours; Jacques Anquetil (5 Tours, 2 Giros, 1 Vuelta); Eddy Merckx (5 Tours, 5 Giros, 1 Vuelta); Bernard Hinault (5 Tours, 3 Giros, 2 Vueltas); Miguel Indurain (5 Tours, 2 Giros); and all winning performances of riders in the years from 2006 to 2013. The total number of time trials is $N=100$. As we already noted, the current sample differs from the previous Armstrong time-trial study in which analyses were restricted to limited distances of the trials (50-61 km). In the present study, we did not apply this restriction. Apart from Armstrong $(N=7)$ and all other riders who faced trials between 50 and $61 \mathrm{~km}(N=27), 66 \%(N=66)$ of the remaining sample consists of different cyclists who faced a large variation in trial distances: $8.2-137 \mathrm{~km}$. Moreover, $73 \%(N=73)$ of the sample consists of performances of multiple winners (including Armstrong) and 27\% $(N=27)$ relates to accomplishments of riders in the 2006-2013 periods. Of the latter riders, eleven comprised the Doping Group, while the No Doping Group consisted of sixteen riders.

Table 1 indicates that Coppi and Armstrong won the fewest trials and Anquetil, Merckx, and Hinault the most. Further note that the riders did not win all the trials in the tours in which they ranked first and that some of their performances occurred during the same tour, i.e., some tours included several time trials at different stages in the races. Compared to the other riders, Armstrong's trials show the smallest range in distance. One-way ANOVA yielded significant differences in mean time trial distances between riders, $F(7,92)=12.00, p \leq .001, \eta_{p}{ }^{2}=.48$. On average, the Italian 'campionissimo' Fausto Coppi faced the longest and the Belgian Eddy Merckx the shortest trials. Auxiliary pair wise comparisons, in which we corrected for unequal variances between groups by Games-Howell test, subsequently showed that Armstrong's distances significantly differed from the distances of Merckx and the riders in the Doping and No Doping Group. These results imply that cyclists' performances may be influenced by the variation in the length of the trials for which we should statistically control when examining our research questions.

Correlations between the variables $(d f=100)$ revealed that the relationship between year of competition and distance is not significant, $r=-.08(p=.41)$. With advancing years riders delivered significantly faster mean $\mathrm{km} / \mathrm{h}$ performances, $r=.73(p \leq .001)$, while the relationship with mean time performances is much weaker, $r=-.21(p \leq .05)$. Larger distances of the trials are weakly associated with mean $\mathrm{km} / \mathrm{h}$ performances, $r=-.24(p$ $\leq .05)$, but show a robust relationship with mean time performances, $r=.98(p \leq .001)$. Both correlations show that increasing distances are associated with slower performances. However, distance explains $96 \%$ of the variation in riders' mean time performances, but only $5.8 \%$ in their mean $\mathrm{km} / \mathrm{h}$ performances. This disparity is due to the fact that the latter variable already incorporates the distances of the trials. This entails that $\mathrm{km} / \mathrm{h}$ performances do not permit independent statistical estimations of the influence of trial distances, while time performances do. Moreover, the term time trial implies that the criterion to appraise riders' achievements in these individual races is about time, not $\mathrm{km} / \mathrm{h}$. Accordingly, we decided to focus on riders' mean time performances to address our research questions. ${ }^{1}$ The correlation between the two performance measures, $r=-.40(p \leq .001)$, indicates a common variance of $16 \%$ between the two variables.

\subsection{Analyses}

To answer our research questions, we conducted multiple regression analyses (OLS) in which riders' mean time performances served as the criterion. Using the hierarchical regression procedure developed by Hayes [18] and Preacher and Hayes [19], we estimated the influence of the rider main effect, controlled for competition year and trial distances, on the variation in cyclists' mean time performances. With respect to research question 1 and 2, we aggregated the data of all other cyclists and compared them to Armstrong (dummy coded: Armstrong = 1; other riders $=0$ ) and mean centered the control variables (year of competition $M=1985$; distance $M=43.83 \mathrm{~km}$ ). As regards the third research question, we compared performances of the Doping Group / Armstrong (= 1; $N=$ 18 in total) to performances delivered by riders in the No Doping Group ( $=0 ; N=16$ ). In these analyses, we used the same control variables as put forward above.

Findings of the analyses will further yield estimated and residual performances. We checked whether these performances deviated from normality and / or could be considered outliers. Besides, very slow or fast performances or very short or long time trials may have exerted an undue influence on the regression findings, jeopardizing the stability and validity of the regression model. We therefore checked for influential cases. Given the current sample, the critical leverage value for influential cases is $h \geq .12$. We conducted analyses using INDIRECT $[18,19]$ that runs under IBM-SPSS ${ }^{\circledR}$ (v. 20).

\section{Results}

\subsection{Research Questions 1 and 2}

\footnotetext{
${ }^{1}$ Findings regarding riders' mean $\mathrm{km} / \mathrm{h}$ performances closelyreplicated the results of [6] as well as the current findings. Initially, the unadjusted rider main effect was not significant, $b=2.16 \mathrm{~km} / \mathrm{h}\left(\Delta R^{2}=0.02, p=.11\right)$. Armstrong $\left(M_{\mathrm{km} / \mathrm{h}}=49.37\right)$ raced somewhat faster than the other riders $\left(M_{\mathrm{km} / \mathrm{h}}=47.21\right)$. Distance accounted for $b=-0.41 \mathrm{~km} / \mathrm{h}$ and competition year for $b=2.24 \mathrm{~km} / \mathrm{h}$ in the rider- $\mathrm{km} / \mathrm{h}$ performance relationship. After adjusting for the influence of the two control variables, the rider main effect was strongly reduced, $b=0.33 \mathrm{~km} / \mathrm{h}(p=.74)$, explaining $0.1 \%$ of the performance differences between riders. Across trials, Armstrong $\left(M_{\mathrm{km} / \mathrm{h}}=47.66\right)$ raced somewhat faster than the other cyclists $\left(M_{\mathrm{km} / \mathrm{h}}=\right.$ 47.33). Results further revealed that the Doping Group / Armstrong $\left(M_{\mathrm{km} / \mathrm{h}}=49.55\right)$ raced slightly slower $(b=-1.17 \mathrm{~km} / \mathrm{h})$ than the No Doping Group $\left(M_{\mathrm{km} / \mathrm{h}}=50.72\right)$. This difference is far from significant $\left(\Delta R^{2}=.032, p=.33\right)$ and occurred after adjusting for the effect of the two control variables in the rider-km/h performances relationship (year of competition, $b=0.14 \mathrm{~km} / \mathrm{h}$; distance $b=0.41 \mathrm{~km} / \mathrm{h}$ ).

Findings additionally showed that riders raced faster over time with $b=$ $0.13 \mathrm{~km} / \mathrm{h}$ per year $\left(\Delta R^{2}=.528, p \leq .001\right)$, while the influence of distance was weak, $b=-0.03 \mathrm{~km} / \mathrm{h}\left(\Delta R^{2}=.033, p \leq .01\right)$. These findings imply that $\mathrm{km} / \mathrm{h}$ performances do not enable estimations of the influence of trial distances on riders' $\mathrm{km} / \mathrm{h}$ achievements $(r=-.24)$, while time performances do $(r=.98)$. Last, the positive relationship between competition year and mean $\mathrm{km} / \mathrm{h}$ performances $(r=.73)$ we found in the current study is subject to the same criticism, described in the Discussion section of this contribution and in Lodewijkx and Verboon [6]. We argue that the correlation is spurious, since it is influenced by the significant between-rider variation in trial distances, and $\mathrm{km} / \mathrm{h}$ performances do not allow independent statistical estimations of this influence.
} 
Figure 1 summarizes findings of the analyses. The unstandardized path coefficients to the left of Figure 1 show that the rider variable and the two control variables co-vary. Compared to the aggregated other cyclists, the coefficients indicate that Armstrong, on average, competed in later years ( $b=17.34$ years) and faced somewhat larger trial distances $(b=13.32 \mathrm{~km})$. There is no co-variation between competition year and trial distance, $b=-0.09(p=.46)$. Regarding our first research question, Figure 1 shows the unadjusted rider main effect, not yet controlled for the influence of the two covariates. It indicates a non-significant difference of $b=-773 \mathrm{~s}$ between Armstrong vs. the aggregated other riders, which explains $1.2 \%$ of the performance variation between them $\left(\Delta R^{2}=.012, p=.28\right)$. Across trials, Armstrong $\left(M_{\text {time }}=\right.$ $4102 \mathrm{~s})$ raced slower than the other riders $\left(M_{\mathrm{time}}=3329 \mathrm{~s}\right)$. To the right of Figure 1, the path coefficients of the two control variables can be seen. As regards our second research question, the findings indicate a significant progress in riders' time performances of $b=-12.23 \mathrm{~s}$ per year, which explains $\Delta R^{2}=.045$ of the performance differences between riders. The analyses further yielded a strong influence of distance, indicating an increase of $b=$ $84.64 \mathrm{~s}$ in time performance $\left(\Delta R^{2}=.933\right)$ to a kilometer increase in the distances of the trials.

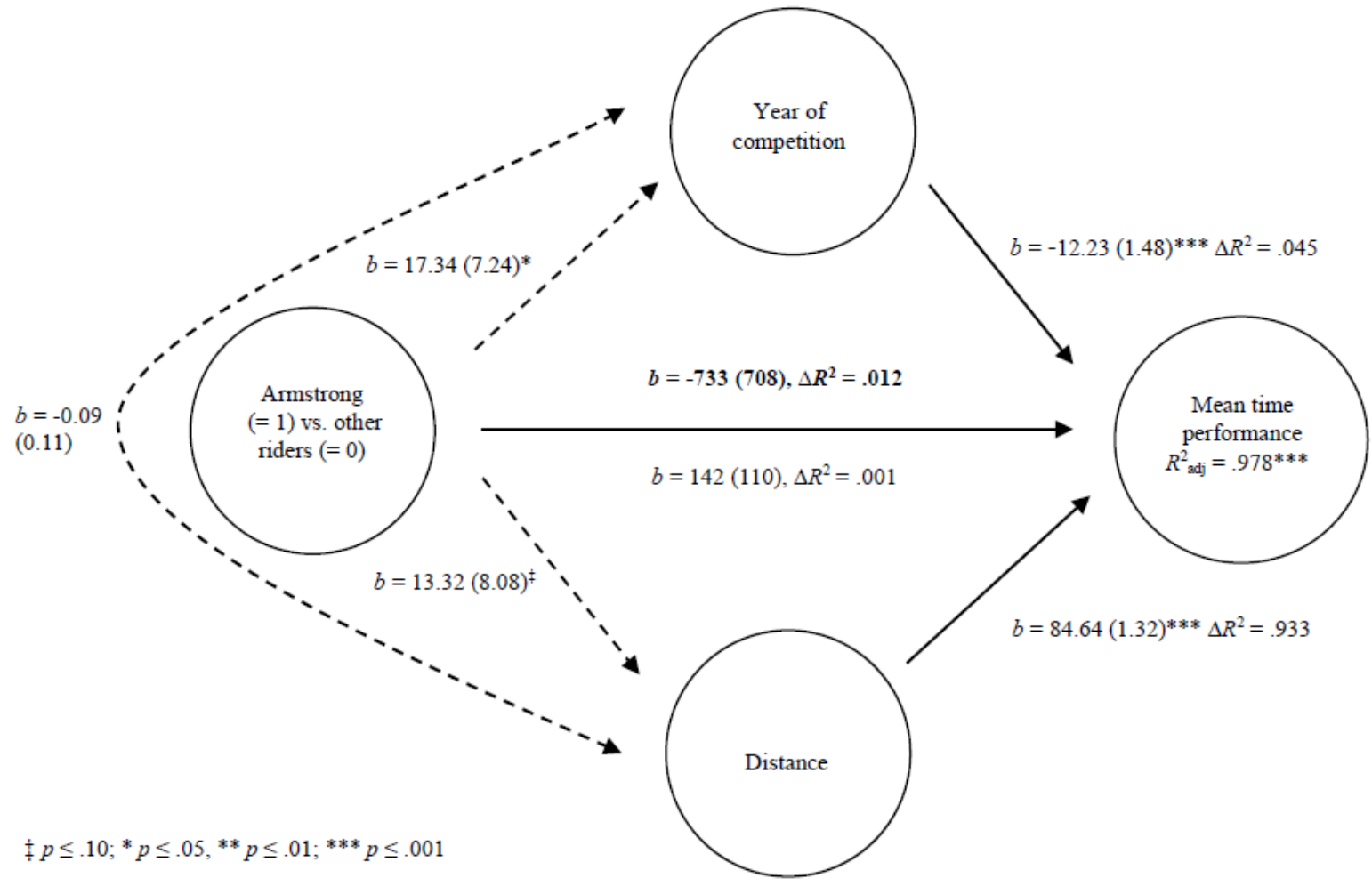

Figure 1. Regression analyses of variables explaining differences in mean time performances (seconds) between Armstrong vs. other riders. Presented are unstandardized regression weights $(b)$ and associated standard errors $\left(S E_{b}\right)$ in parentheses. The weights and $S E_{b}$ are in seconds per year, or in seconds to a kilometer increase in the distances of the time trials. Broken arrows indicate co-variances between variables. The unadjusted rider main effect is in bold type face

We next examined the (indirect) ways in which the two control variables affected performance differences between Armstrong vs. the other riders. Results showed that competition year accounted for a decrease of $b=-212$ $\mathrm{s}$ and trial distances for a huge increase of $b=1127 \mathrm{~s}$ in the rider-time performance relationship. Combined, the two control variables are responsible for a difference of $b$ $=915 \mathrm{~s}$ in this relationship (i.e., $1127-212=915 \mathrm{~s}$ ). Figure 1 shows what remains of the rider main effect, after we controlled for the two indirect effects. As noted, the unadjusted rider main effect amounted to $-773 \mathrm{~s}$ and the two control variables accounted for a performance difference of $915 \mathrm{~s}$ between the riders. As a result, the adjusted main effect shows that Armstrong ultimately performed $b=142 \mathrm{~s}$ faster than the other riders did (i.e., $915-773=142 \mathrm{~s})$. This difference is not significant ( $p$ $=.20$ ) and explains $\Delta R^{2}=.001$ of the differences in riders' time performances. Across trials, Armstrong realized $M$ time $=3251 \mathrm{~s}$ and the other riders $M_{\text {time }}=3393 \mathrm{~s}$. The three variables in the model explained a significant $R_{\text {adj }}^{2}=.978$ of the variation in riders' time trial achievements, $F(3,96)$
$=1479.25, p \leq .001$, to which distance contributed by far the most (93.3\%) and the rider main effect the least $(0.1 \%)$. These results disconfirm research question 1 . Regarding research question 2, our results yielded a small linear progress in riders' achievements with advancing years, which accounts for $4.5 \%$ of the performances differences between riders.

\subsection{Research Question 3}

Results of the regression analyses examining differences between riders of the Doping Group / Armstrong vs. the No Doping Group ${ }^{2}$ initially produced a

${ }^{2}$ We also analyzed differences between riders of the Doping Group ( $N$ $=11)$ vs. the No Doping Group $(N=16)$, excluding Armstrong. Findings supported previous results. The analyses initially produced a significant difference of $b=-614 \mathrm{~s}\left(R_{\text {adj }}^{2}=.129, p=.07\right)$. The Doping Group $\left(M_{\text {time }}=\right.$ $3224 \mathrm{~s}$ ) raced slower than the No Doping Group $\left(M_{\text {time }}=2610 \mathrm{~s}\right)$. After controlling for the influence of competition year $(b=-43 \mathrm{~s})$ and trial distance ( $b=583 \mathrm{~s}$ ) the adjusted rider main effect amountedto $b=-74 \mathrm{~s}$, which is not significant $\left(\Delta R^{2}=.001, p=.29\right)$. Again, the Doping Group delivered somewhat slower performances $\left(M_{\text {time }}=2904 \mathrm{~s}\right)$ than the No Doping Group $\left(M_{\text {time }}=2830 \mathrm{~s}\right)$. 
significant difference of $b=-955 \mathrm{~s}\left(R_{\mathrm{adj}}^{2}=.254, p \leq .001\right)$. Across trials, the Doping Group / Armstrong $\left(M_{\text {time }}=3565\right.$ s) raced slower than the No Doping Group $\left(M_{\text {time }}=2610 \mathrm{~s}\right)$. Subsequent assessment of the influence of the two control variables indicated that competition year accounted for $b$ $=-11 \mathrm{~s}$ and trial distance for $b=898 \mathrm{~s}$ of the differences in the rider-time performance relationship. Combined, the two control variables are thus responsible for a decrease $b$ $=887 \mathrm{~s}$ in this relationship $(898-11=887 \mathrm{~s})$. After controlling for the indirect influence of the two covariates, the adjusted rider main effect amounted to $b=-68 \mathrm{~s}$ (887$955=-68 \mathrm{~s})$, which is not significant $(p=.35)$ and explains $\Delta R^{2}=.01$ of the differences in riders' time performances. Scrutiny of the adjusted means showed that, across trials, the Doping Group / Armstrong again accomplished somewhat slower performances $(M$ time $=$ $3148 \mathrm{~s}$ ) than the No Doping Group ( $M_{\text {time }}=3080 \mathrm{~s}$ ). The three variables in the analysis explained $R_{2 \mathrm{adj}}=.975$ of the variation in riders' time trial achievements, $F(3,30)=$ 430.35, $p \leq .001$. As with the previous analyses, distance contributed the most $(96.7 \%)$ to these explained differences and the rider main effect the least (1\%). These findings refute research question 3 .

\subsection{Outliers, Influential Cases, and Normality}

The three panels in Figure 2 present the partial regression plots for competition year, distance, and the rider main effect, respectively. To determine outliers, we applied the rigorous 95\%-confidence interval $(z \geq \pm 1.96$ or $\pm 2 S D$ from the sample mean), while conventionally the criterion of $\mathrm{z} \geq \pm 3.30$ is used (or $\pm 3 S D$ with $N<1000$ ) [20]. Panel C in Figure 2 shows that only two of Armstrong's performances $(-1.54<z<1.15)$ surpassed the bounds of the $68 \%-C I-$ that is $\pm 1 S D$ from the sample mean - and none went beyond the limits of the 95\%-CI. Panel C shows only one rider whose relatively fast performance exceeded the bandwidth of the 95\%-CI: Spanish rider Miguel Indurain $(z=-2.31$, first trial Tour 1992). One rider demonstrated a very slow performance. It concerns Fausto Coppi $(z=5.26)$, who had also a large leverage value $(h=0.23)$ owing to the fact that he faced a formidable 137-km long trial in the 1949 Tour. Besides, riders' observed, predicted and residual time performances did not depart from normality (Kolmogorov-Smirnov test, zs $\leq 0.98, p s \geq .29$ ), indicating there are no signs of any 'abnormal' fast or slow performances among the riders, including Armstrong. Last, the absence of a relationship between predicted and residual time performances, $r=.00$, reveals a good fit of the regression model.

Table 2. Influence of Year of Competition and Trial Distance on Riders' Mean Time Performances (Seconds) when Excluding Armstrong and Riders Involved in Doping Affairs

\begin{tabular}{lcccc}
\hline Riders Included / Excluded & Variables & $b$ & $S E_{b}$ & $R_{\text {adj }}^{2}$ \\
\hline A. All included $(N=100)$ & Year & -12.23 & 1.48 & .98 \\
& Distance & 84.64 & 1.32 & \\
B. Armstrong excluded & Year & -12.29 & 1.49 & \multirow{2}{*}{.98} \\
$(N=93)$ & Distance & 84.71 & 1.33 & \\
C. Armstrong and Doping Group & Year & -12.21 & 1.72 & \multirow{2}{*}{.98} \\
excluded $(N=82)$ & Distance & 85.20 & 1.40 & \\
D. Armstrong, Doping, and No & Year & -19.75 & 2.60 & \multirow{2}{*}{.99} \\
Doping Group excluded $(N=66)$ & Distance & 86.13 & 1.35 & \\
\hline Notes: All estimates $p \leq .001$. The $b$-weights and $S E_{b}$ are in seconds per \\
year, or in seconds to a kilometer increase in the distances of the time \\
trials.
\end{tabular}
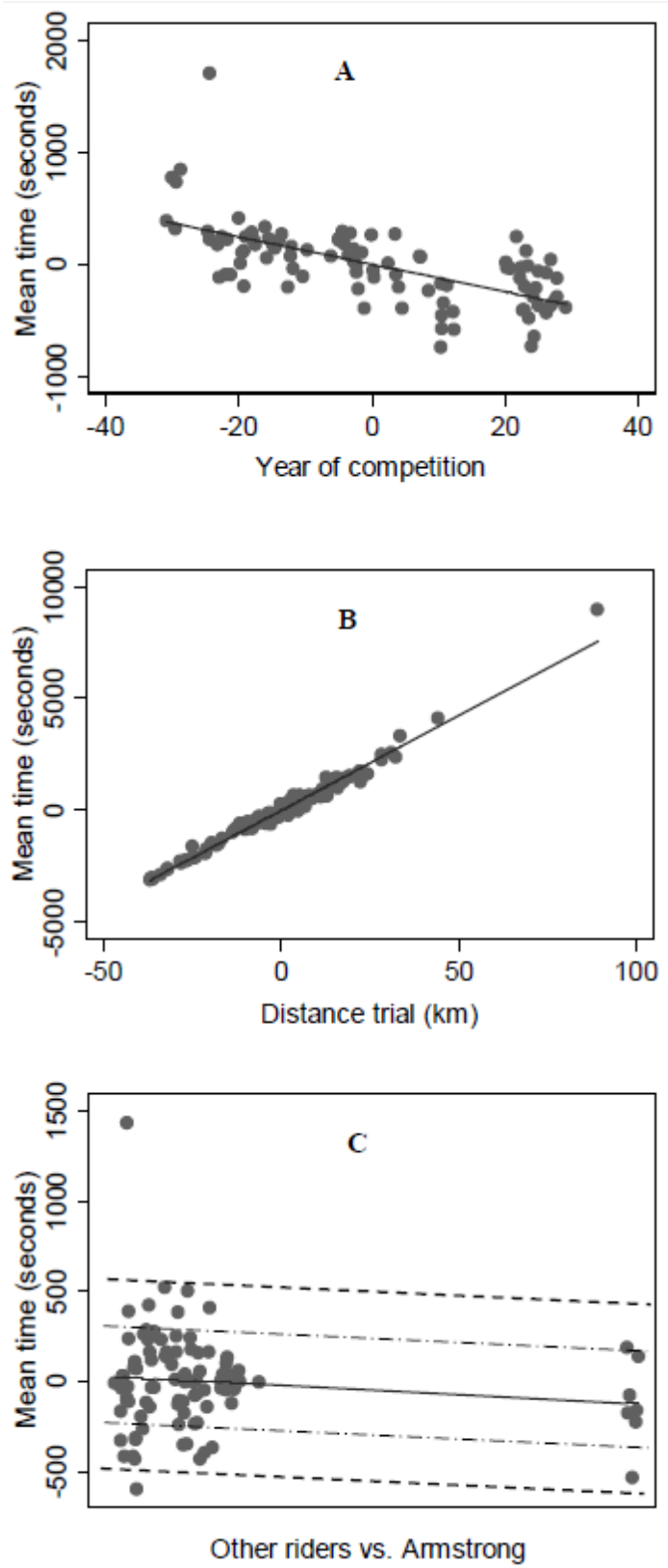

Figure 2. Partial regression plots of riders' mean time performances predicted by year of competition (Panel A), trial distances (Panel B), and other riders vs. Armstrong (Panel C). Variables are mean centered. The dashed line in Panel C presents the 95\%-CI, and the dashed-dotted line the $68 \%-\mathrm{CI}$

\subsection{Auxiliary Analyses}

To validate the results relating to our research questions and to more closely examine the robust relationship we found between trial distances and riders' mean time performances, we performed two series of supplementary analyses. As will be shown, the resulting findings have implications for the interpretation and evaluation of Armstrong's doping-induced wins.

In the first series, we progressively excluded performances of Armstrong, the Doping and No Doping Group from the regression analyses. Findings can be seen in Table 2. Panel A shows the results obtained for the total sample: Competition year, $b=-12.23 \mathrm{~s}$; distance, $b=$ 84.64 s. Panel $\mathrm{B}$ reveals the findings after excluding Armstrong's data. It shows that the unstandardized regression weights for competition year ( $b=-12.29 \mathrm{~s})$ and trial distances ( $b=84.71 \mathrm{~s}$ ) hardly differ from the weights 
obtained for the total sample. The minimal differences concern hundredths of seconds. The same conclusion holds after we additionally excluded performances of the Doping Group from analyses, which are presented in Panel C: Competition year, $b=-12.21 \mathrm{~s}$; distance $b=$ 85.20 s. In Panel D we left out performances of riders of the No Doping Group. This analysis yields an insight into the development in riders' achievements from Fausto Coppi to Miguel Indurain (1949-1995). For these riders, competition year accounted for a progress in speed of $b=$ -19.75 s per year, while distance reduced their performances with $b=86.13 \mathrm{~s}$ per kilometer increase in trial distance. These observations indicate that the yearly progress in speed is somewhat faster for the riders in the 1949-1995 periods compared to the years thereafter and that it took the same riders more time per kilometer increase in trial distances. Importantly for our research questions, however, the results further entail that the time trial achievements of the Armstrong as well as the Doping Group are no exemption to the linear relationship obtained for the total sample. Concerning the second series of auxiliary analyses we conducted, Table 3 summarizes the performance relationship for all separate (groups of) riders. Reckoning the strong correlation we found between the two variables, it is not surprising to observe that distance explains considerable amounts of variation in riders' mean time performances. Seven of the eight standardized regression weights indicate nearly perfect relationships, $\beta$ $=.98-.99$, with $R_{\text {adj }}^{2}=.96-.99$. The striking exception to these results pertains to Armstrong with $\beta=.64$ and $R^{2}$ adj $=.29(p=.12)$. He is the only rider for whom the estimate is not significant. The positive weights in Table 3 indicate that all riders perform slower per kilometer increase in trial distances. Seemingly, Armstrong's $b=41.66 \mathrm{~s}$ designates that he realized the fastest performance compared to all other winners. However, as noted, his weight is not significant. This can be explained by the strong variability in his performances $\left(S E_{b}=22.11\right)$, which is by far the largest relative to all other riders. To compare, Merckx's performances are exemplified by an impressive, very low variability of only $S E_{b}=0.99 \mathrm{~s}$ across his nineteen trial wins. As to the remaining riders, their variability ranges between $S E_{b}=2.34-4.48 \mathrm{~s}$.

Table 3. Riders' Mean Time Performances Regressed on Distances of the Time Trials

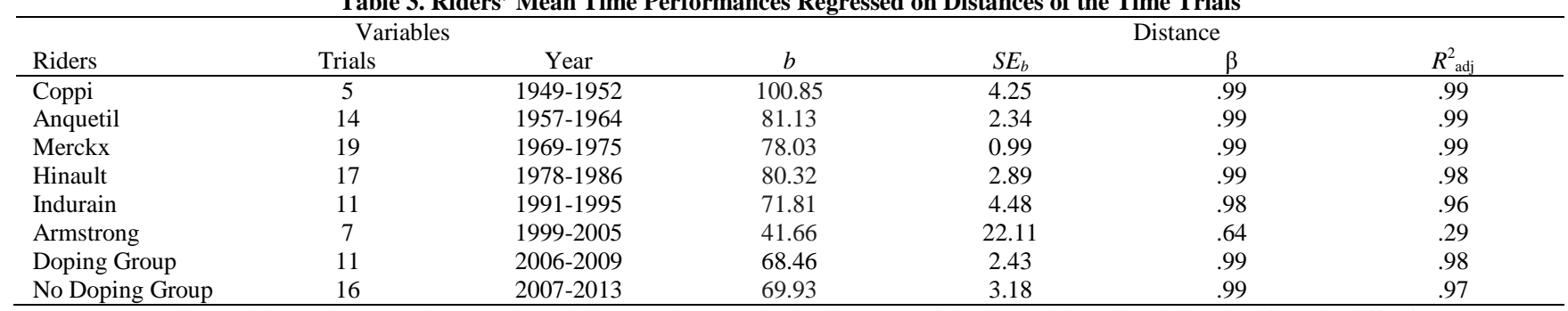

Notes: Regression weights and SEs are in seconds per kilometer increase in the distances of the time trials. All weights significantly differ from zero, $p$ $\leq .001$, with the exception of Armstrong.

\section{Discussion}

Findings did not support our first research question. The statistical evidence suggests that Armstrong's performances do not appear to be superior, but quite comparable to the achievements of the other riders we investigated. Our second research question related to the logic used in the appeal to ignorance, which presupposed a strong relationship between competition year (with the associated doping use) and riders' performances. Findings revealed that this relationship is significant but weak $\left(\Delta R^{2}\right.$ $=.045$ ) and that it is dwarfed by the profound impact of the distance variable on riders' mean time performances $\left(\Delta R^{2}=.933\right)$. Considering our third research question, we found no performance differences between Armstrong along with other riders who engaged in doping practices in the years between 2006 and 2013 vs. a group of riders that were not associated with such practices in the same era.

Regarding outliers, normality and influential cases, results showed that, across the three Grand Tours and the years between 1949 and 2013, only one of the 100 riders demonstrated a comparatively fast performance that could not be predicted by the year in which he competed or the distances of the time trials: Spanish time trial specialist Miguel Indurain. We emphasize that his performance also cannot be considered special, since we took the stringent 95\%-CI as the criterion to determine outliers, rather than the conventionally employed $\pm 3 S D$-criterion. Besides, all performances were normally distributed, indicating that Armstrong's wins were also far from being 'abnormal.'
Last, since only one rider (Coppi) was identified as an influential case our regression findings appear to be stable and valid.

\subsection{Validity}

The low number of Armstrong's time trials $(N=7)$ may have jeopardized the statistical conclusion validity of our findings. Thus, there might be differences in speed between Armstrong and the other riders, while we erroneously may have concluded that such differences are absent. However, the agreement in findings between the current study and two other Armstrong studies [6,11] we conducted thus far is substantial. In these studies we approached Armstrong's wins using different performances and different samples, adding validity to our findings and conclusions. Besides, when accounting for the year in which riders' competed as well as the distances of the time trials, Panel C of Figure 2 shows that Armstrong's achievements are randomly scattered across performances of the other riders. For these reasons we argue that our findings are sound and, hence, that our general conclusion concerning Armstrong's cycling feats is also valid.

\subsection{Armstrong's Inconsistency}

What remains to be clarified is the strong variability we observed in Armstrong's wins. A first explanation may be sought in the restricted range in the distances of his trials (50-61 km). This would make it hard to find any association between distance and time performances. A second explanation may be found in various race-related 
factors which are of the utmost importance for excellent time trial racing [16], such as the conditions of the roads, the number of winding roads on the course, hilly courses, and meteorological circumstances (wind, heat, rain). These circumstances can be regarded as sources of random variation and they may increase the inconsistency in riders' performances, in particular if the number of time trials is low, as is the case with Armstrong. Two of his performances may have been influenced by such circumstances, conceivably leading to comparatively slower performances. In the 2002 Tour, extremely high temperatures may have affected his time trial achievement [15], while in the 2005 Tour his time trial around the St. Etienne region included $\mathrm{Col}$ de la Gachet (altitude $731 \mathrm{~m}$ [15]). However, we emphasize that many of the performances of the riders we investigated may have been subject to similar, difficult race conditions. So, Armstrong is not the only rider who faced extreme weather, or a hilly trial. Further note that the number of trials of Coppi $(N=5)$ is even lower than Armstrong's. Yet, the achievements delivered by the Italian cyclist, who faced much larger distances than Armstrong and who demonstrated his feats in the early years of the Tour and Giro, are far more consistent than performances of the American ex-racer. A third explanation may be found in premeditated considerations. His own ranking and the rankings of his opponents in the general classification may have determined his performances in the different trials. In some trials he may have been forced to perform at maximum level to reach a good standing, while in other trials less maximal performances may have sufficed to consolidate his position in the overall classification. A final explanation may be sought in his doping use. Perhaps in some trials he resorted to banned doping means and methods, while in other he did not. Since we lack verifiable and reliable information concerning these various explanations, we conclude that the reasons for Armstrong's inconsistency remain unclear. Nevertheless, reckoning his doping use, future research should perhaps focus much more on the variation in riders' individual achievements over the years as a means to indirectly identify the effects of doping aids on their performances.

\subsection{Discounting the Argument from Ignorance}

When considering the proposed performance-enhancing effects of the various doping agents Armstrong gave in to, findings of research yield conflicting results. As to testosterone, former UCI president Verbruggen [21] concluded that there is "no real scientific evidence that other drugs used in the athletic community, such as amphetamines and steroids [i.e., testosterone, our comment] had any measurable effect on endurance.” The conclusion concerning the putative effects of testosterone on cyclists' endurance performances is corroborated by Kuipers [22]. Lundby and Olsen [23] summarized results of laboratory studies examining the relationship between artificial epo administration and improvements in aerobic exercise capacity, measured by maximum oxygen uptake $\left(\mathrm{VO}_{2 \max }\right)$. They observed that epo administration led to 8$12 \%$ improvements in this capacity. For blood doping the estimates are 5-10\% [24]. The ergogenic effects of blood transfusions are labelled "gigantic" in a recent study by Lundby, Robach and Saltin [25].
Alternatively, however, other research into the effects of epo and blood doping on cyclists' performances suggests that these effects are overestimated [22,26] and may even lack scientific evidence [27]. Findings of Lundby and Olsen [23] and related studies [24,25] as well as judgments of the World Anti-Doping Agency [14] undoubtedly indicate that Armstrong's use of epo and blood transfusions may have given him a potent advantage over his forerunners to whom he was compared in the current study. Note, however, that these riders won their trials chiefly in the years before the massive doping schemes surfaced in professional cycling, that is, before the introduction of epo and blood doping in the cycling world in the 1990s and beyond [28]. Many of his precursors thus lacked the assumed advantages of the modern, advanced doping agents which were obtainable to the American ex-racer. Conversely, results of the more critical studies [26,27] essentially entail that these advantages are exaggerated. We argue that the null results we obtained concerning Armstrong's expected superior achievements in the current study agree with the latter conclusion. The same conclusion also holds true for the lack of significant performance differences between the riders of the Doping Group / Armstrong vs. the No Doping Group.

Then again, critics could argue that our study suffers from several, major methodological drawbacks. One flaw poses that the wins of all cyclists we investigated most likely came about through doping use, including the victories of the No Doping Group. Due to this inestimable conclusions concerning 'abnormal' achievements of the American ex-racer, let alone the other riders. The second fault states that we just poor cold water on an intrinsically flawed research method, since we lack essential control variables to account for any performance differences between riders, owing to the fact that the circumstances under which cyclists practiced their sport improved considerably over time [10,11,12,13,15,17,29,30,31]. For instance, we disregarded the variation in course altitudes in addition to improvements in road and race conditions. Performances delivered by riders prior to the advent of clipless pedals (1985) and aerobars (1989) cannot be compared to performances achieved by riders in succeeding years who raced with disk wheels and with advanced equipment tested in wind tunnels. Note that the latter confounding variables do not constitute systematic errors, but sources of variation which can be estimated. Our failure to include any of these confounding variables in our study may indeed have undermined our findings. However, the soundness of this criticism depends on the estimated strength of the relationships of these variables with riders' achievements over the years. It can be deduced that these relationships will be weak.

All these critical remarks fail to consider the enormous impact of one single, race-related variable which is by far the most important to explain the variation in riders' performances in time trial racing over the years: The distances of the trials. This variable nearly perfectly predicts riders' achievements, $\beta=.98-.99$ and $R_{\text {adj }}^{2}=.96-$ .99 (except for Armstrong). Furthermore, regarding the total sample, the three variables included in the regression model explained $R^{2}$ adj $=.978$ of the differences in riders' wins. For performances in the modern era, that is, the sportive achievements of the Doping Group / Armstrong 
and the No Doping Group, the three variables yielded $R$ 2adj $=.975$. This implies that only a slight $2.2-2.5 \%$ of these differences may be explained by the confounding variables alluded to above, which may include riders' doping use. What is more, our results further revealed that competition year explained $4.5 \%$ of the variation in riders' time performances, designating a slow but steady progress in their time trial achievements with advancing years. This progress can also be seen in Table 1, Table 2 and Table 3, and Panel A in Figure 2. Note that this progress incorporates the influence of the unknown and perhaps incalculable variation in conditions under which the trials took place over time as well as the impact of technological improvements in equipment. The remarkable low percentage of unexplained performance differences in addition to the minor yearly progress we observed, entail that the influence of potential confounding variables including riders' doping use - on riders' time trial achievements will not be very strong. Importantly, the inclusion of some of these variables in the regression model could perhaps reduce the robust impact of trial distances, but will also increase the chance that even more performance differences between riders will be explained, thereby diminishing the amount of unexplained error variance to practically zero. All these arguments refute the logic employed in the appeal to ignorance and rebut the critique on our research method.

To conclude, our observations demonstrate that discussions about the (putative) effects of doping in the cycling world may involve false arguments. Carroll [9] notes that the use of these arguments becomes more tempting among 'believers.' Thus, for people who believe in the effects of doping, the lack of evidence to the contrary may be germane to supporting their belief. Whom the cap fits, let him wear it.

\section{Conflict of Interests}

The authors declare that they have no conflict of interests regarding the publication of this research.

\section{References}

[1] A. Dilger, B. Frick and F. Tolsdorf, "Are athletes doped? Some theoretical arguments and empirical evidence", Contemporary Economic Policy, 25 (4), 604-615, 2007.

[2] W. Voet, Breaking the chain, London, Yellow Jersey Press / Random House, 2001.

[3] T. Hamilton and D. Coyle, The secret race, New York, Bantam Books, 2012.

[4] USADA, Statement from USADA CEO Travis T. Tygart regarding the U.S. Postal Service Pro Cycling Team doping conspiracy, 2012. Available http://cyclinginvestigation.usada.org

[5] USADA, Reasoned decision of the United States Anti-Doping Agency on disqualification and ineligibility, 2012. Available http://cyclinginvestigation.usada.org

[6] H. F.M. Lodewijkx and P. Verboon, "Lance Armstrong's era of performance - Part I: Are his time trial performances much different from other winners?”, Journal of Athletic Enhancement, 2 (1), 2013.

[7] T. V. Perneger, "Speed trends of major cycling races: Does slower mean cleaner?", International Journal of Sports Medicine, 31, 261-264, 2010

[8] H. Vandeweghe, Who has faith in cyclists anymore? [In Dutch: Wie gelooft de coureurs nog?], Ghent (Belgium), Borgerhoff and Lamberigts, 2013.
[9] R. T. Carroll, The skeptic's dictionary: A collection of strange beliefs, amusing deceptions, and dangerous delusions, Hoboken (NJ), John Wiley and Sons, 2003.

[10] N. El Helou, G. Berthelot, V. Thibaut, M. Tafflet, H. Nassif, F. Campion., ...J.-F. Toussaint, "Tour de France, Giro, Vuelta, and classic European races show a unique progression of road cycling speed in the last 20 years”, Journal of Sports Sciences, 28 (7), 789-796, 2010.

[11] H. F. M. Lodewijkx, "Lance Armstrong’s era of performance Part III: Demonstrating the post hoc fallacy", American Journal of Sports Science and Medicine, 1 (4), 63-70, 2013.

[12] H. F. M. Lodewijkx and B. Brouwer, "Some empirical notes on the 'epo epidemic' in professional cycling”, Research Quarterly for Exercise and Sport, 82 (4), 593-608, 2011.

[13] H. F. M. Lodewijkx and B. Brouwer, "Tour, Giro, Vuelta: Rapid progress in cycling performance starts in the 1980s", International Journal of Sports Science, 2 (3), 24-31, 2012.

[14] WADA. World Anti-Doping Agency Prohibited list, 2013. Available

http://www.wada-ama.org/en/World-Anti-DopingProgram/Sports-and-Anti-Doping-Organizations/InternationalStandards/Prohibited-List/.

[15] D. Magnier, P. Picq, M. Debreilly, P. Zingoni, H. Haffreingue, and J.-L Bey, Cycling remembered. [In French: Mémoires du cyclisme], 2013. Available http://www.memoire-du-cyclisme.eu.

[16] A. Lucia, C. Earnest and C. Arribas, "The Tour de France: a physiological review", Scandinavian Journal of Medicine and Science in Sports, 13, 275-283, 2003.

[17] H. F. M. Lodewijkx and P. Verboon, "The Texas sharpshooter in the three Grand Tours (1933-2013): No evidence for superior time trial performances in the epo era", Manuscript submitted for publication, Breda (the Netherlands), Open University of the Netherlands, 2014.

[18] A. F. Hayes, "INDIRECT: An SPSS-macro for estimating indirect path coefficients in regression models", 2013. Available http://afhayes.com/spss-sas-and-mplus-macros-and-code.htmll.

[19] K. J. Preacher and A. F. Hayes, "Asymptotic and resampling strategies for assessing and comparing indirect effects in multiple mediator models”, Behavior Research Methods, 40, 879-891, 2008.

[20] B.G. Tabachnick and L.S. Fidell, Using multivariate statistics (4th ed.), Boston, Allyn and Bacon / Pearson Education Company, 2001.

[21] H. Verbruggen, “The EPO epidemic in sport”, Bloodline Reviews, 1, 3-4, 2001.

[22] H. Kuipers, "Putative effects of doping in cycling" [In Dutch: "Vermeende effecten van doping in de wielersport"], Nederlands Tijdschrift voor Geneeskunde, 150, 2643-2645, 2006.

[23] C. Lundby, C. and N.V. Olsen, "Effects of recombinant human erythropoietin in normal humans", Journal of Physiology, 589, 1265-1271, 2011.

[24] J. R. Bytomski, C. T. Moorman III and D. MacAuley, Oxford American handbook of sports medicine, Oxford, Oxford University Press, 2010.

[25] C. Lundby, P. Robach and B. Saltin, "The evolving science of detection of 'blood doping' ", British Journal of Pharmacology, 165, 1306-1315, 2012.

[26] H. F. M. Lodewijkx, B. Brouwer, H. Kuipers and R. van Hezewijk, "Overestimated effect of epo administration on aerobic exercise capacity: A meta-analysis", American Journal of Sports Science and Medicine, 1 (2), 17-27, 2013.

[27] J. A. A. C. Heuberger, J. M. Cohen-Tervaert, F. M. L. Schepers, A. D. B. Vliegenthart, J. I. Rotmans, J. Daniels ... A. F. Cohen, "Erythropoietin doping in cycling: Lack of evidence for efficacy and a negative risk-benefit", British Journal of Clinical Pharmacology, 75 (6), 1406-1421, 2013.

[28] D. H. Catlin, C. K. Hatton and F. Lasne, Abuse of recombinant erythropoietins by athletes. In G. Moulineux, M. A. Foote and S. G. Elliott (Eds.) Erythropoietins and erythropoiesis, Basel, Birkhäuser Verlag, 2006, 205-228.

[29] B. F. Brewer, "Commercialization in professional cycling 19502001: Institutional transformations and the rationalization of doping”, Sociology of Sport Journal, 19, 276-301, 2002.

[30] W. Fotheringham, Fallen angel: The passion of Fausto Coppi, London, Yellow Jersey Press, 2009.

[31] B. Maso, The sweat of the Gods, Norwich (UK), Mousehold Press, 2005. 